\title{
Preface: A Literary History of Politics
}

In February 2002, when the world was debating what should be done about Iraq, Europeans reached for a metaphor they like to apply to Americans. President George W. Bush and his advisors, they protested, were behaving like Hollywood cowboys. Writing in the Wall Street Journal, R. James Woolsey, the former director of Central Intelligence, accepted that label as a badge of pride. Yes, he agreed, you could compare us to Gary Cooper in High Noon (his favorite movie). When evildoers descended on the marshal's town, only he was willing to stand up to them. His neighbors all turned out to be appeasers or pacifists or cowards or potential collaborators, but the marshal wouldn't "give up doing his duty just because everyone else found excuses to stay out of the fight." 1

Meanwhile, Dominique de Villepin, Secretary General to the President of France, and soon to become French Foreign Minister, spun out a parallel but different narrative. He had just published Le Cent Jours ou l'Esprit de Sacrifice, his account of Waterloo, another legendary gunfight. In his review, Denis MacShane, Britain's Minister for Europe, called it "simply a thrilling read ... His description of characters is as good as any popular historian and his sense of narrative pace carries the reader along," though the book might leave one with the impression that Napoleon won the battle. Waterloo, wrote de Villepin, "glows with the aura worthy of a victory," for as a diplomat and a prolific author, he always insisted that France could not be France unless she pursued "epic collective adventures." 2

So here we have two nations following two narratives on a diplomatic collision course, an episode that illustrates the power of stories to steer politics. You may object that politics is really a matter of national interests, however this begs the question: what are nations interested in? Of course they want power, wealth, trade, land, and security. But political actors also act out stories, which can have a force and a momentum of their own, and which may 
not always serve the more material national interests. Foreign policies inspired by Napoleon or Gary Cooper do not necessarily benefit France or the United States, and they may not have served the personal interests of M. Chirac or Mr. Bush. All politicians, however, tell stories, whether they are grand Bonapartist myths or homey Reaganesque anecdotes, and these stories can drive policy. After all, a few years ago Americans catapulted an obscure politician into the White House largely because they loved reading his life story.

All politicians are authors. Very few of them write anything like an 800page critique of French poetry, as Dominique de Villepin has, but they all create and publish texts: oral texts, printed texts, filmed texts, broadcast texts. Most politicians, like most authors, are hacks who simply recycle clichés; a few are genuinely creative visionaries. But either way, what they write (or have others write) sets politics in motion. And obviously all politicians are actors, usually performing from a crafted script, but occasionally improvising.

Therefore, we can write political history as literary history. That is, we gain a deeper understanding of politics if we employ the methods developed by literary historians, especially theatre historians and historians of the book. We can ask of politicians the same questions that these scholars ask of authors. What did they read? When they wrote, what were their generic models? How were their writings refashioned by editors, publishers, literary agents, researchers, co-authors, lawyers, and censors? How were their political careers made and unmade by the sociology and economics of authorship, print technology, the structure of media ownership, the machinery of publicity and distribution, book reviewers, and the demands of the literary marketplace? How did they achieve the kind of dramatic effects that are so important in politics? Which literary circles did these political actors move in? Which audiences did they appeal to? How did readers respond to what they wrote, and did that feedback cause them to revise their methods of composition? What can we discover by comparing the successive drafts and editions of their works? And how were those writings translated into other languages and other media, especially film and television? (This study defines "literature" broadly, to include journalism, historical writing, movies, and broadcasting.) When we address these issues, we delve into a mostly unexplored dimension of politics, and we may be able to explain certain kinds of political behavior that might otherwise seem baffling.

Winston Churchill is an ideal subject for experimenting with this new methodology. Winner in 1953 of the Nobel Prize in Literature, a tremendously successful middlebrow author, he clearly could have made a handsome living from his pen even if he had never been elected to public office. In the Churchill Archives at Cambridge, one out of eight boxes is devoted to his literary affairs. And yet scholars have scarcely touched on that side of his life. He may be 
one of the most intensively studied individuals of modern times, according to Historical Abstracts, but he has only a handful of entries in the MLA Bibliography. Some entries refer to an altogether different Winston Churchill, an American novelist (1871-1947) of the Progressive era. Manfred Weidhorn and Paul Alkon wrote appreciative literary criticism of the British Churchill, and perceptive analyses of the composition of The Second World War and A History of the English-Speaking Peoples have been produced by David Reynolds and Peter Clarke. ${ }^{3}$ But this volume has a different and broader objective: it surveys all of Churchill's important writings, reconstructs (as far as we can) his reading and theatre-going experiences, and assesses their impact on his politics. For Churchill, politics and literature were two sides of the same career, impossible to prise apart. His political goals and methods were shaped by what he read in books and saw on the stage. In turn, he recast his political experiences as literature, inevitably with some artistic license. In fact he made important policy decisions and composed memoranda with a view toward how they would appear on the page, in the grand story that he spent his life composing. He was an artist who used politics as his creative medium, as other writers used paper.

Like most radical ideas, this method of writing history is not entirely new. We have studies of the literary diets of Thomas Jefferson, ${ }^{4}$ William Gladstone, ${ }^{5}$ Adolf Hitler, ${ }^{6}$ Harold Macmillan, ${ }^{7}$ John F. Kennedy, ${ }^{8}$ and Barack Obama, ${ }^{9}$ not to mention Nixon at the Movies. ${ }^{10}$ But they are still only a handful: we are only beginning to grasp how far politics and literature overlap. Like Churchill, Douglas Hurd, Jeffrey Archer, Anne Widdecombe, Edwina Currie, Iain Duncan Smith, Jimmy Carter, Barbara Boxer, Newt Gingrich, Barbara Milkulski, William Weld, William S. Cohen, and Gary Hart have all published novels and that only counts recent British and American politicians. If we look to France, the list of political littérateurs becomes practically endless.

And Churchill was clearly not the only statesman of his generation to treat politics as performance art. In the grand drama of the Second World War, he played opposite an unforgettable cast. An earlier dull grey cadre of bourgeois politicians had by then given way to Hitler, Mussolini, Roosevelt, De Gaulle, and Churchill, all of them dazzling actors who played off each other and exploited their own personal charisma. This book, then, is not only a literary biography: it explores the crucial and under-appreciated role of theatre in both politics and armed conflict, by placing Churchill and his contemporaries in the context of theatre history.

Every historical study should begin with these cautious words: "This does not explain everything." I emphasize here the literary and theatrical dimensions of politics because they are neglected and important, but certainly not all-important. The everyday business of government is, by and large, an inartistic routine of nudging bureaucracies, negotiating deals, balancing 
competing interests, and serving constituents. Political historians should not stop doing psephological analyses and research in diplomatic archives. But they should recognize that literature can illuminate political behavior in ways that more conventional methodologies cannot. If the trajectory of an atomic particle follows no known laws of physics, then it is probably in the grip of an unknown force, something we need to understand and work into our calculations. And the political orbit of Winston Churchill could be breathtakingly eccentric. 


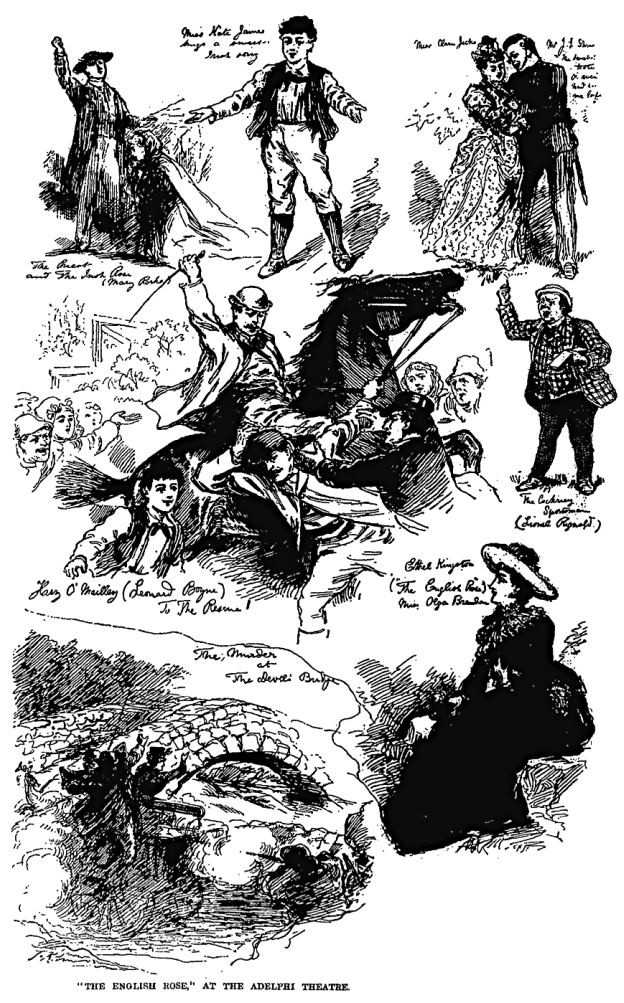

1 Churchill's favorite Irish melodrama, The English Rose (Penny Illustrated Paper, 9 August 1890).

2 Churchill was in the audience for Jules Verne's spectacular melodrama Michael Strogoff, which portrayed an invasion of Russia a half-century before Operation Barbarossa.

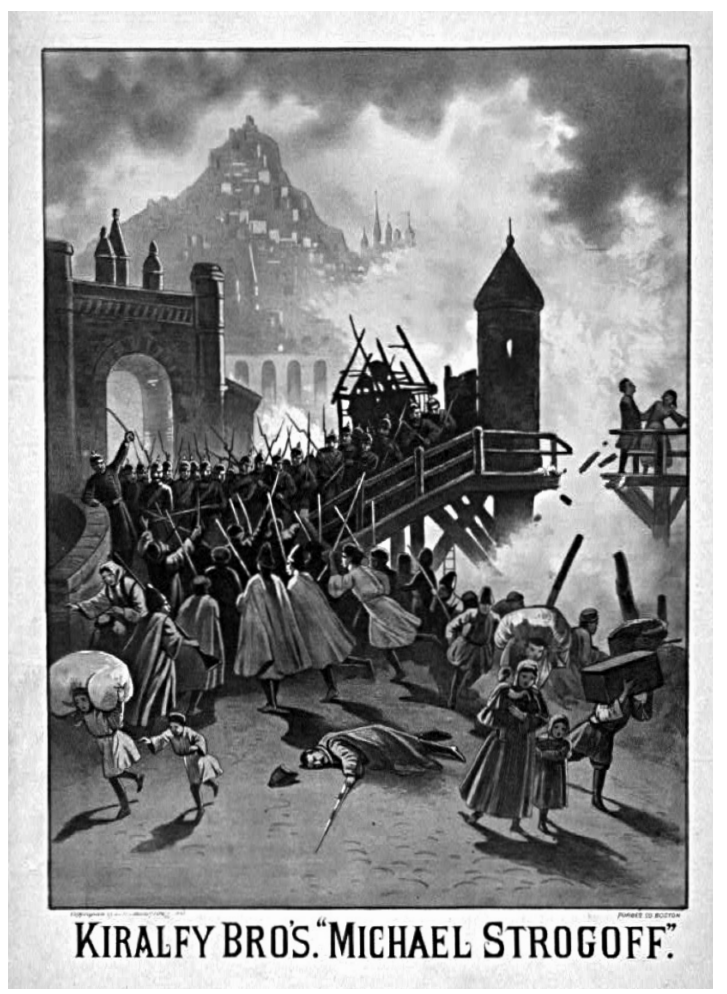




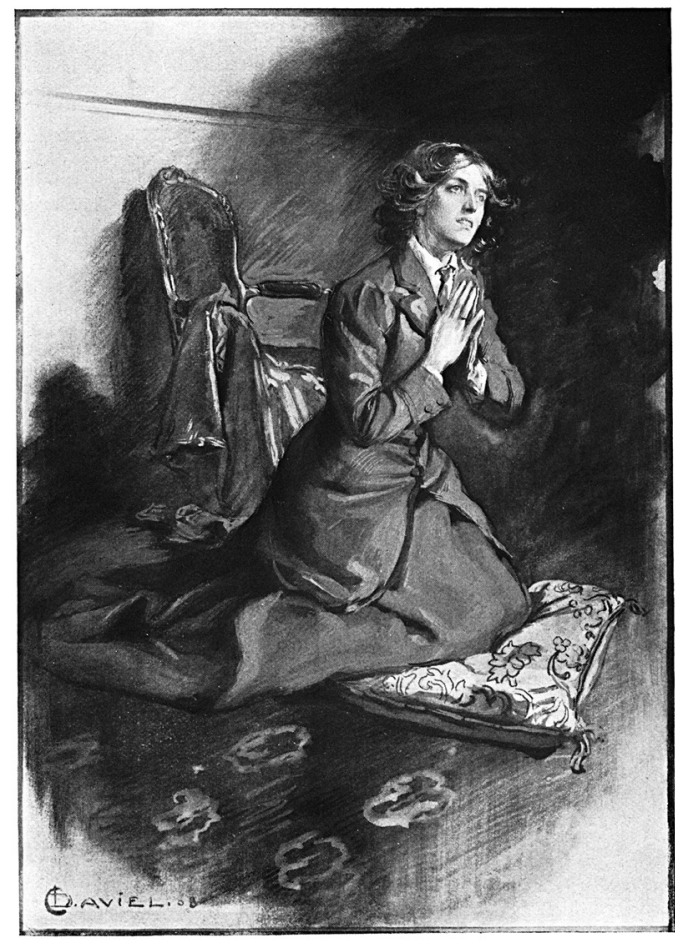

SHE PRAYED FOR THE VICTORY OF THE REBEL SHE LOVED OVER HER HUSBAND, THE PRESIDENT.

3a and 3b From a 1908 illustrated paperback edition of Savrola.

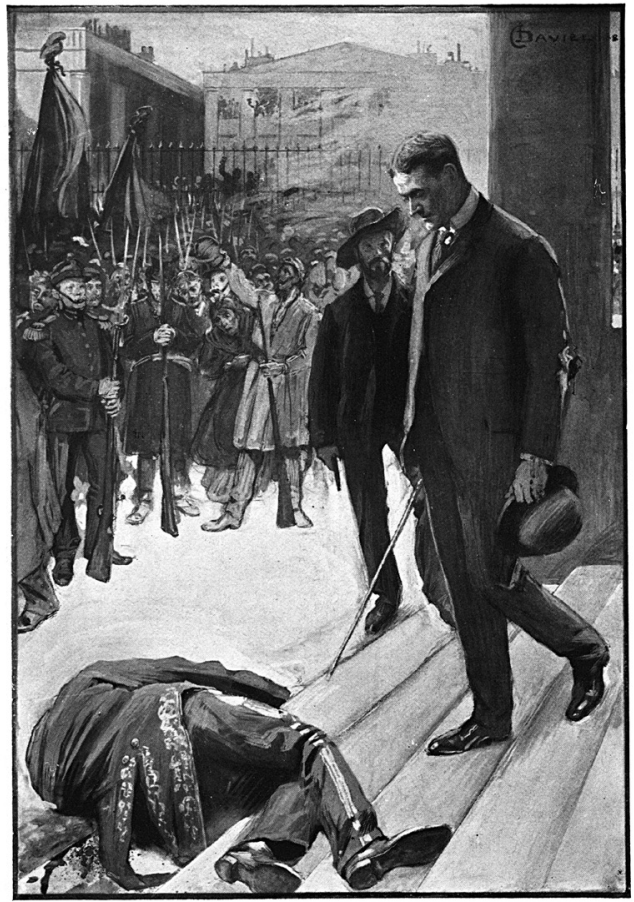

ANTONIO MOLARA LAY ON THE THREE LOWEST STEPS OF Frontisbiece. 1 THE ENTRANCE OF HIS PALACE. 




4 A highly romanticized contemporary newspaper cartoon imagines Churchill's exploits in the Boer War. 


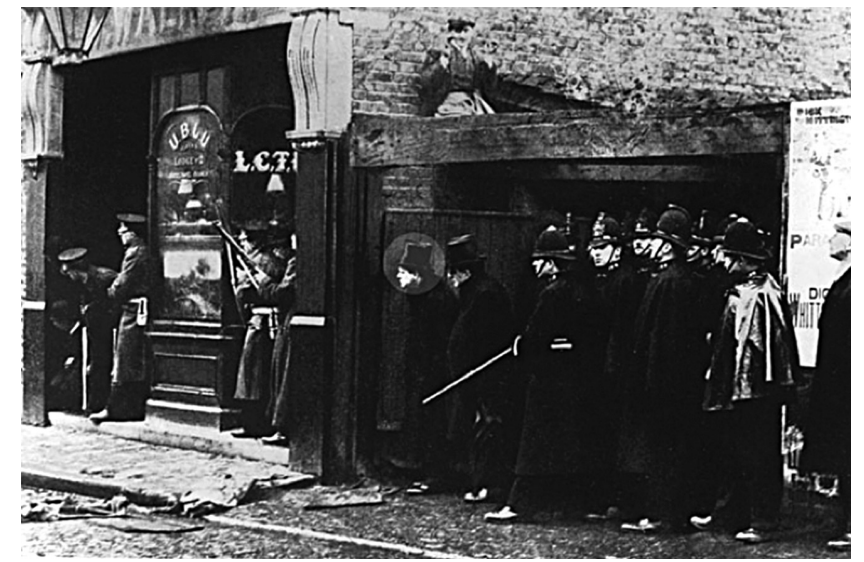

5 The Siege of Sidney Street - which in a sense was the reenactment of Savrola.

6 Self-portait in self-doubt, around 1920.



7 David Low imagines Churchill as a British dictator commanding all authors to serve his cult of personality (Evening Standard, 19 July 1928).

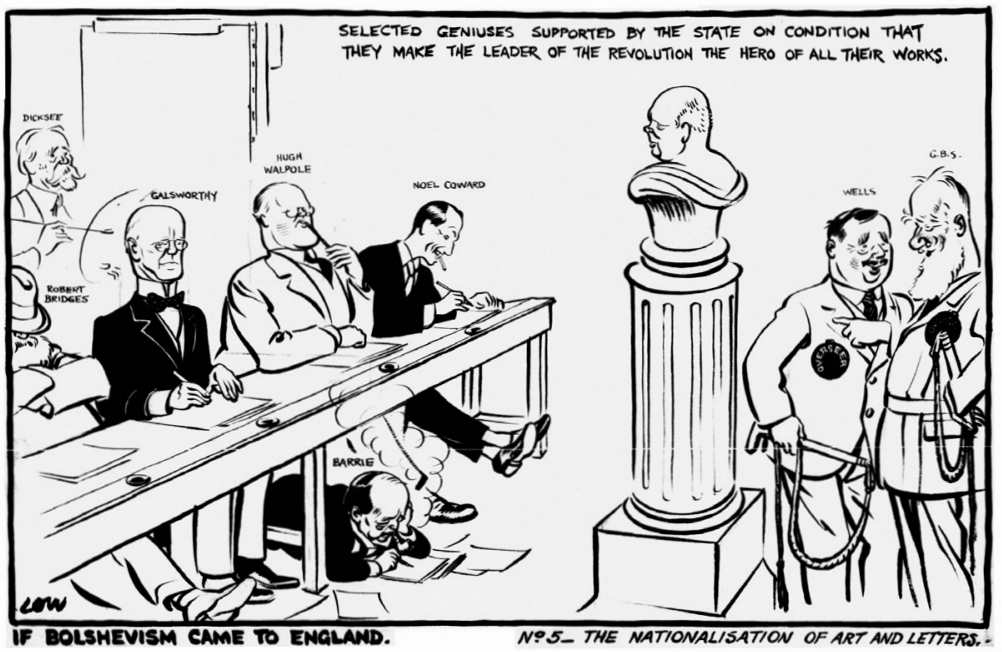






8 The Churchill-Wells Controversy, pencil and wash drawing by Max Beerbohm, 1920. Churchill: "You were only 14 days in Russia!" Wells: "Your mother's an American!" 


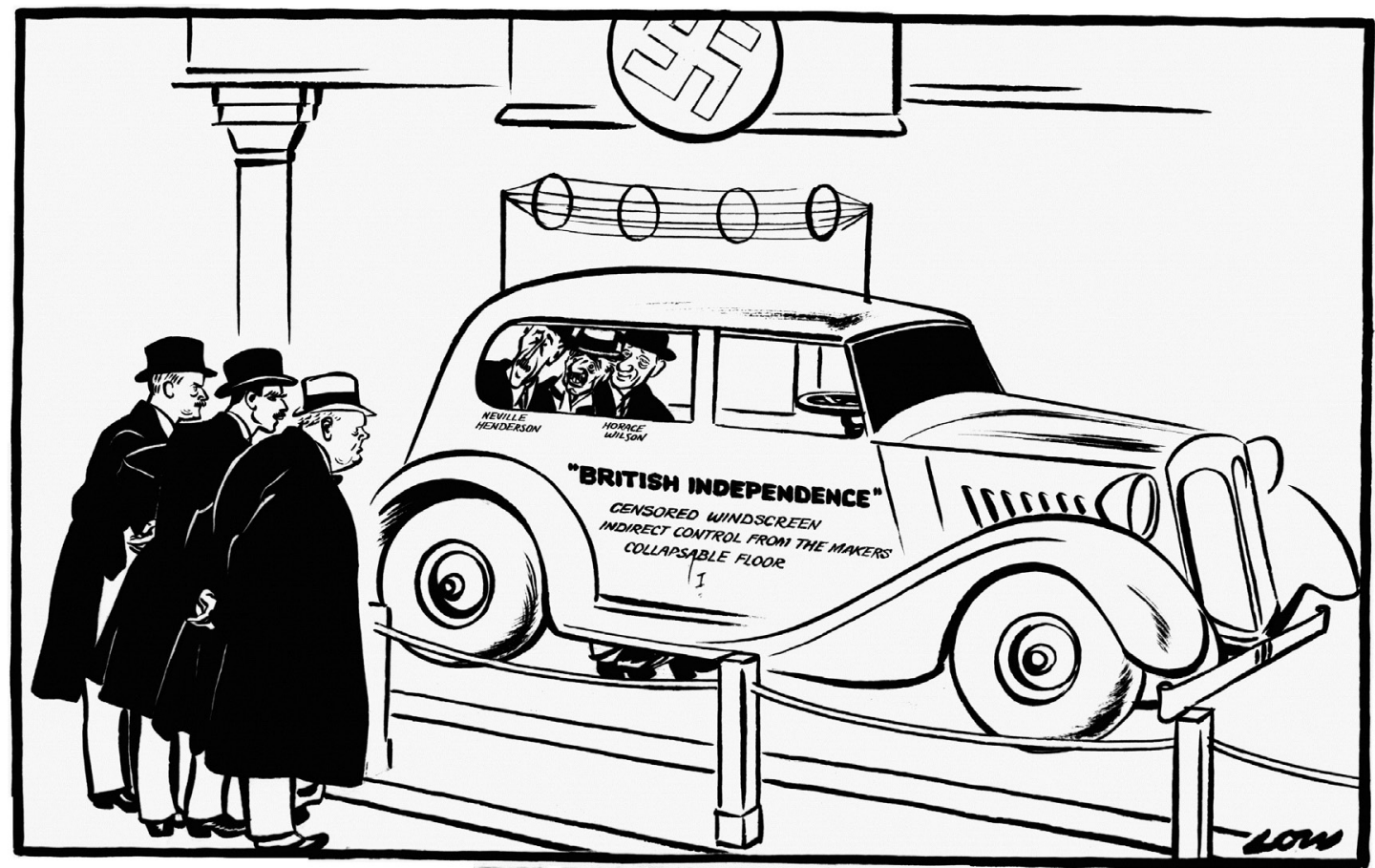

ThaAl of a NEW MOOJL

10 David Low on pro-appeasement censorship, with Duff Cooper, Anthony Eden, and Churchill casting a cold eye (Evening Standard, 14 October 1938). 


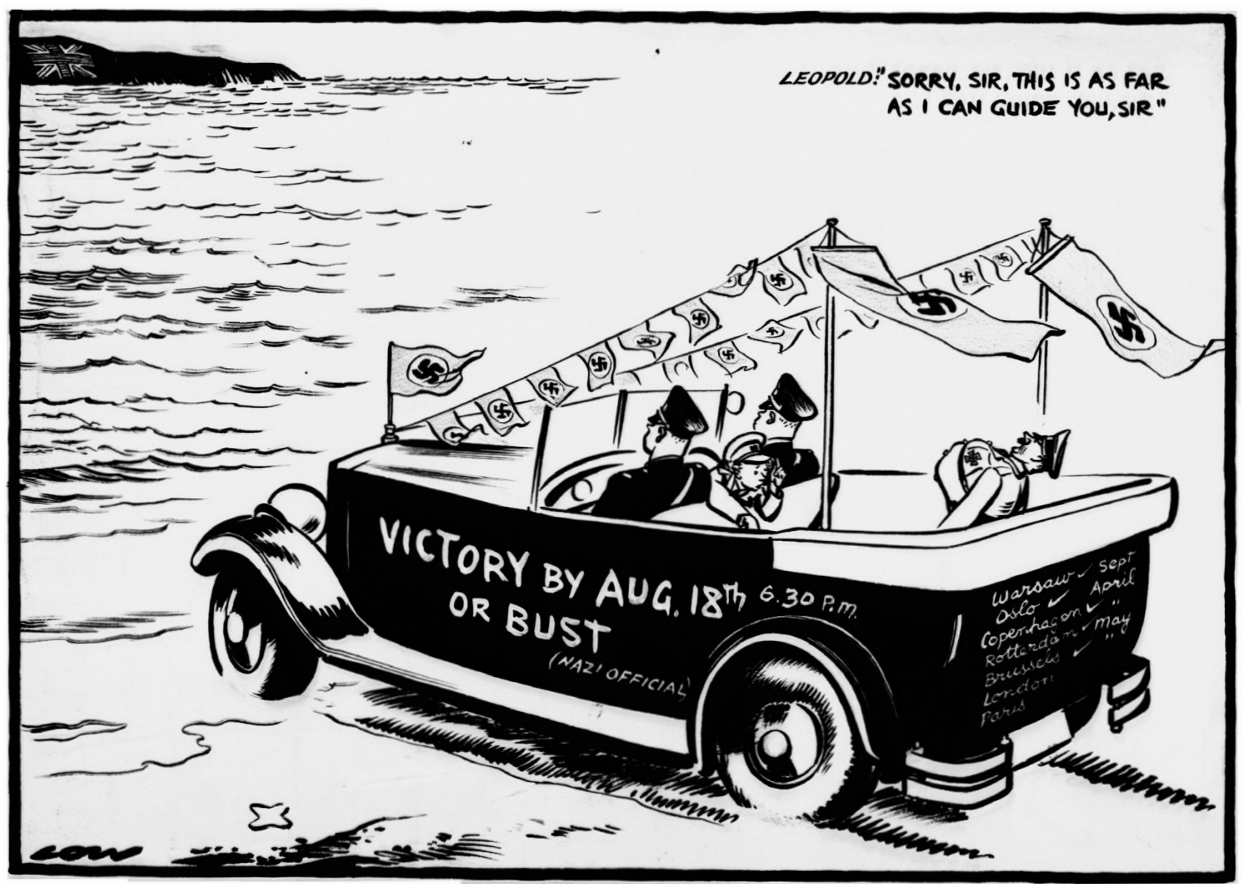

TRIUMPHAL TOUR

11 After the surrender of the Belgian Army, David Low meant to ridicule Hitler's prophesies of victory, but this cartoon may have had the opposite effect on British morale (Evening Standard, 30 May 1940).

12 Young John F. Kennedy autographs his early assessment of Churchill, Why England Slept, for actor Spencer Tracy, November 1940.

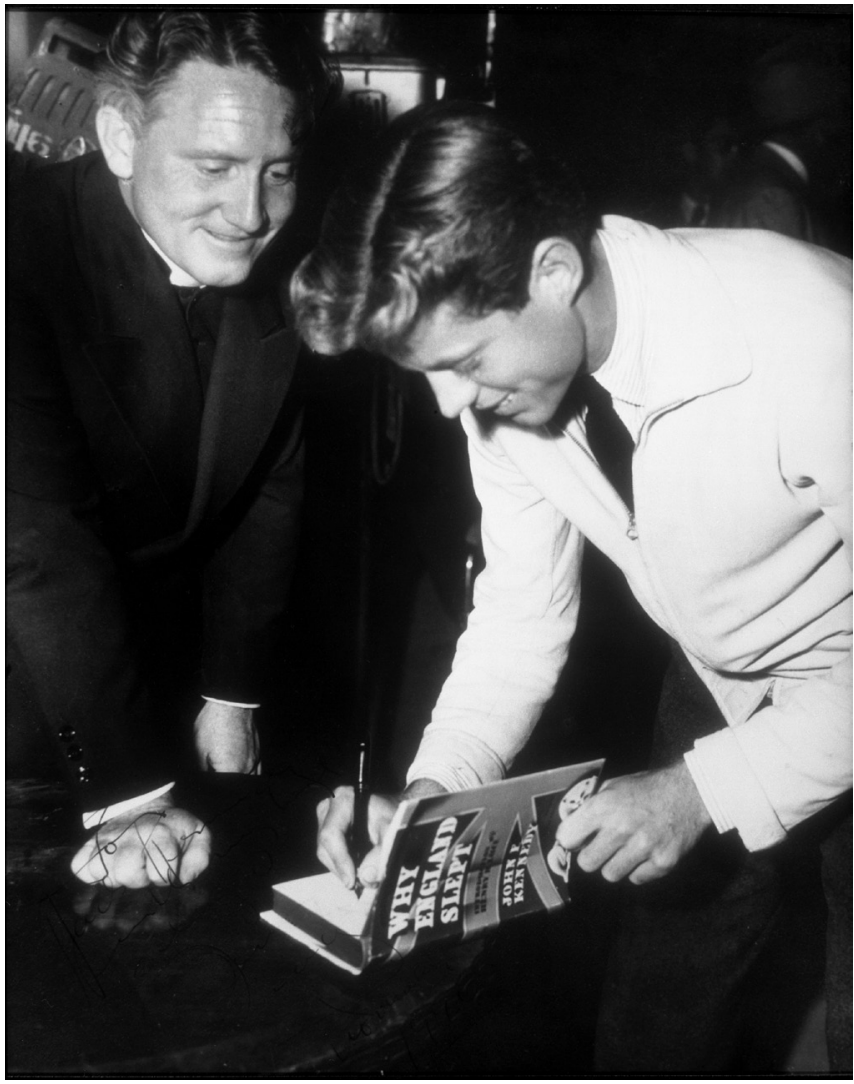

